\title{
Construction Approach to Maintain Composite Action for Continuous Composite Girders
}

\author{
Alfarabi Sharif ${ }^{1}$, Mohammad Samaaneh ${ }^{2}$ \\ ${ }^{1}$ King Fahd University of Petroleum and Minerals \\ Dhahran 31261, Saudi Arabia \\ fmsharif@kfupm.edu.sa \\ ${ }^{2}$ An-Najah National University \\ Nablus, Palestine \\ Mohammad_samaaneh@yahoo.com
}

\begin{abstract}
For continuous composite girders, loss of composite action over interior supports leads to strength and stiffness reduction. This paper is presenting experimental program on a new construction approach to maintain composite action at negative moment regions. Carbon fibber reinforced polymer (CFRP) sheet bonded to top of concrete slab at negative moment region for continuous composite girders. Four two-span continuous composite girders tested to failure each with a total length of five meters. CFRP sheet thickness is the only variable considered in the testing program. Girders designed to develop full composite action between concrete slab and steel section. For negative moment region, shear connectors designed to develop full composite action between CFRP sheet, slab reinforcement and steel section. Steel section designed as fully compact to eliminate any secondary failures. Experimental results demonstrated the effectiveness of this construction approach to maintain the composite action at negative moment region for service loading. The stiffness and strength of the continuous composite girders improved.
\end{abstract}

Keywords: carbon fibber reinforced polymer (CFRP), continuous composite girders, composite action, structural strengthening

\section{Introduction}

For continuous composite steel-concrete girders, loss of composite action over interior supports lead to stiffness and strength reduction. The concrete slab over the interior supports develop cracks and becomes ineffective to maintain the composite action with the steel section. In design, the concrete slab at negative moment region ignored, and the steel section assumed to act alone or compositely with the longitudinal reinforcements. Several researchers tried to overcome the loss of composite action at negative moment regions by internal or external pre-stressing. Basu et al.[1] experimentally evaluated two span continuous composite girder by pre-stressing the concrete slab over the interior support. The concrete slab cast in two stages, first stage of casting over interior support followed by pre-stressing the slab compositely acting with the steel section. In the second stage, the rest of concrete slab cast at positive moment region. Chen et al. [2] tested three spans continuous composite girders by external pre-stressing. The continuous composite girders pre-stressed by external tendons attached to the steel girders. Both pre-stressing techniques maintained the composite action for service load and improved the strength and stiffness of the continuous composite girders.

In this work, as another alternative to pre-stressing, CFRP sheet bonded to top of concrete slab at negative moment region for continuous composite girders. This construction approach experimentally evaluated to assess its capability to maintain composite action at service load.

\section{Experimental Program}

The detail dimensions of the two-span continuous composite girder tested in this program, shown in Fig. 1. The built up steel section proportioned to eliminate all secondary failures. The composite girder designed to develop full composite action between concrete slab and steel section at positive moment region, and between CFRP sheet and steel section at negative moment region. Shear studs with $19 \mathrm{~mm}$ diameter used to develop the composite action spaced as shown in Fig.1. 


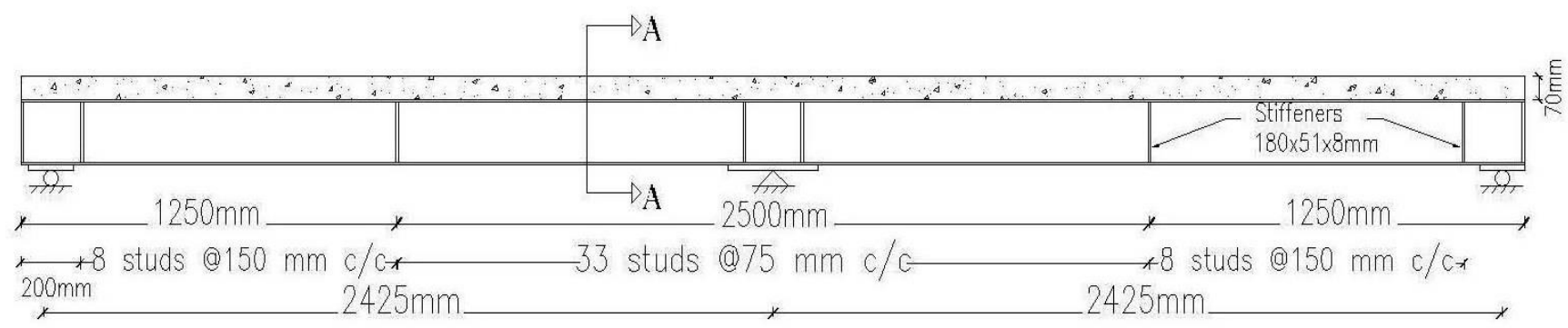

Fig. 1: Dimensions of the two-span continuous composite girder.

The cross section dimensions of the girder shown in Fig. 2. A total number of four girders tested in this program RG, G1, G2 and G3 as listed in Table 1.

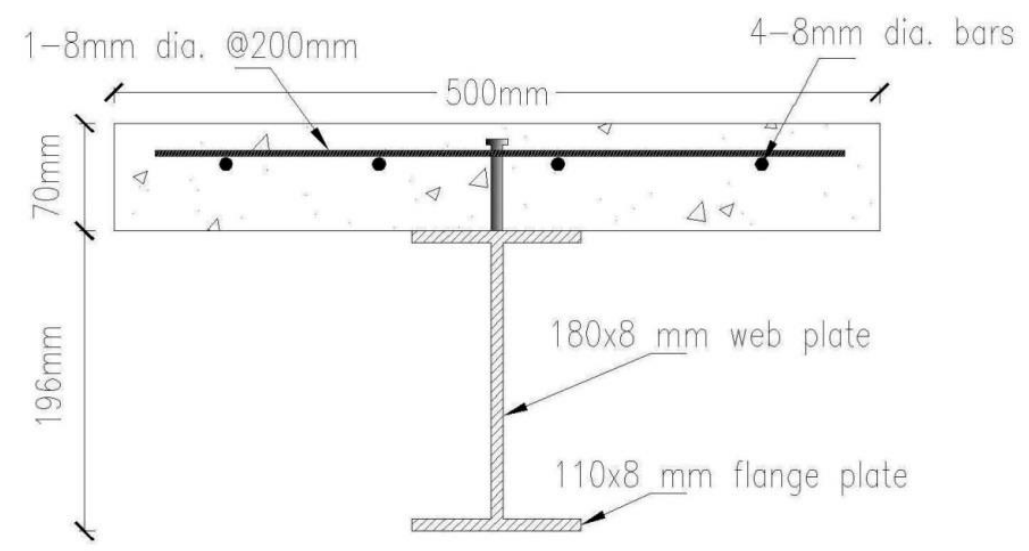

Fig. 2: Section A-A, cross section details.

Table 1: Girder matrix.

\begin{tabular}{|l|c|c|c|c|}
\hline Girder & RG & G1 & G2 & G3 \\
\hline CFRP sheet thickness (mm) & - & 0.131 & 0.262 & 0.393 \\
\hline
\end{tabular}

Girder RG is the reference girder fabricated without CFRP sheet, and girders G1, G2 and G3 with varying CFRP thicknesses bonded to top of concrete slab as shown in Fig. 3. CFRP length taken in accordance with ACI code [3] including development length. The mechanical properties of concrete, steel and CFRP given in Table 2. CFRP sheet bonded to concrete slab using epoxy adhesive consisting of primer base and hardener mixed according to manufacturer specifications. All girders tested under one point load at mid-span as shown in Fig. 3 at a rate of $1.0 \mathrm{kN} / \mathrm{sec}$ to failure. The deflection at mid-span under each step of loading recorded using LVDT (linear variable differential transducer). Strain gauges mounted on steel section, steel reinforcement, concrete slab and CFRP sheet.
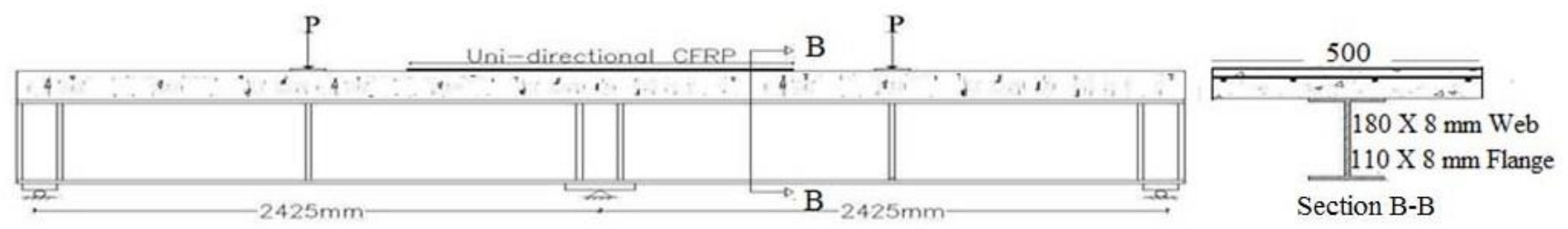

Fig. 3: Composite girder bonded with CFRP at negative moment region. 
Table 2: Mechanical properties of materials.

\begin{tabular}{|c|c|l|c|}
\hline \multicolumn{2}{|c|}{ Concrete } & \multicolumn{2}{c|}{ CFRP } \\
\hline Compressive strength & $26.4 \mathrm{MPa}$ & Tensile strength & $3483 \mathrm{MPa}$ \\
\hline Ultimate strain & 0.0037 & Ultimate strain & 0.015 \\
\hline Steel & \multicolumn{2}{|c|}{ Reinforcement } & Structural \\
\hline Yield strength & \multicolumn{2}{|c|}{$417.7 \mathrm{MPa}$} & $278.6 \mathrm{MPa}$ \\
\hline Yield strain & \multicolumn{2}{|c|}{0.00205} & 0.0014 \\
\hline Ultimate strength & \multicolumn{2}{|c|}{$601.3 \mathrm{MPa}$} & $430.7 \mathrm{MPa}$ \\
\hline
\end{tabular}

\section{Results and Discussion}

The load-deflection curves for all girders shown in Fig. 4. All girders behaved in a linear manner up to yielding of the bottom flange at mid-span. The yielding load $\mathrm{P}_{\mathrm{y}}$ correspond to yielding of bottom flange at mid-span defined as the upper limit of service load. The cracking load $\mathrm{P}_{\text {cr }}$ correspond to load initiating cracks visually inspected in concrete slab over the interior support. The ratio of cracking load to yielding load taken as an indicator for maintaining composite action at negative moment region under service load. The values of $\mathrm{P}_{\mathrm{cr}}$ and $\mathrm{P}_{\mathrm{y}}$, recorded from test observations, given in Table 3 along with their ratio. Girders with CFRP sheet bonded to top of concrete slab G1, G2 and G3 recorded higher values of $P_{\text {cr }}$ and $\mathrm{P}_{\mathrm{cr}} / \mathrm{P}_{\mathrm{y}}$ ratio than girder RG. This clearly confirms that the proposed approach has maintained the composite action at negative moment region under service load. The improvement in strength and stiffness of the girders with CFRP inclusion observed in Fig. 4. Strength and stiffness improvements for girders are directly proportional to the increase in CFRP sheet thickness. Girder G3 has minimal strength and thickness improvement relative to G2. Therefore, the proper CFRP sheet thickness for this continuous composite girder is the one used for girder G2.

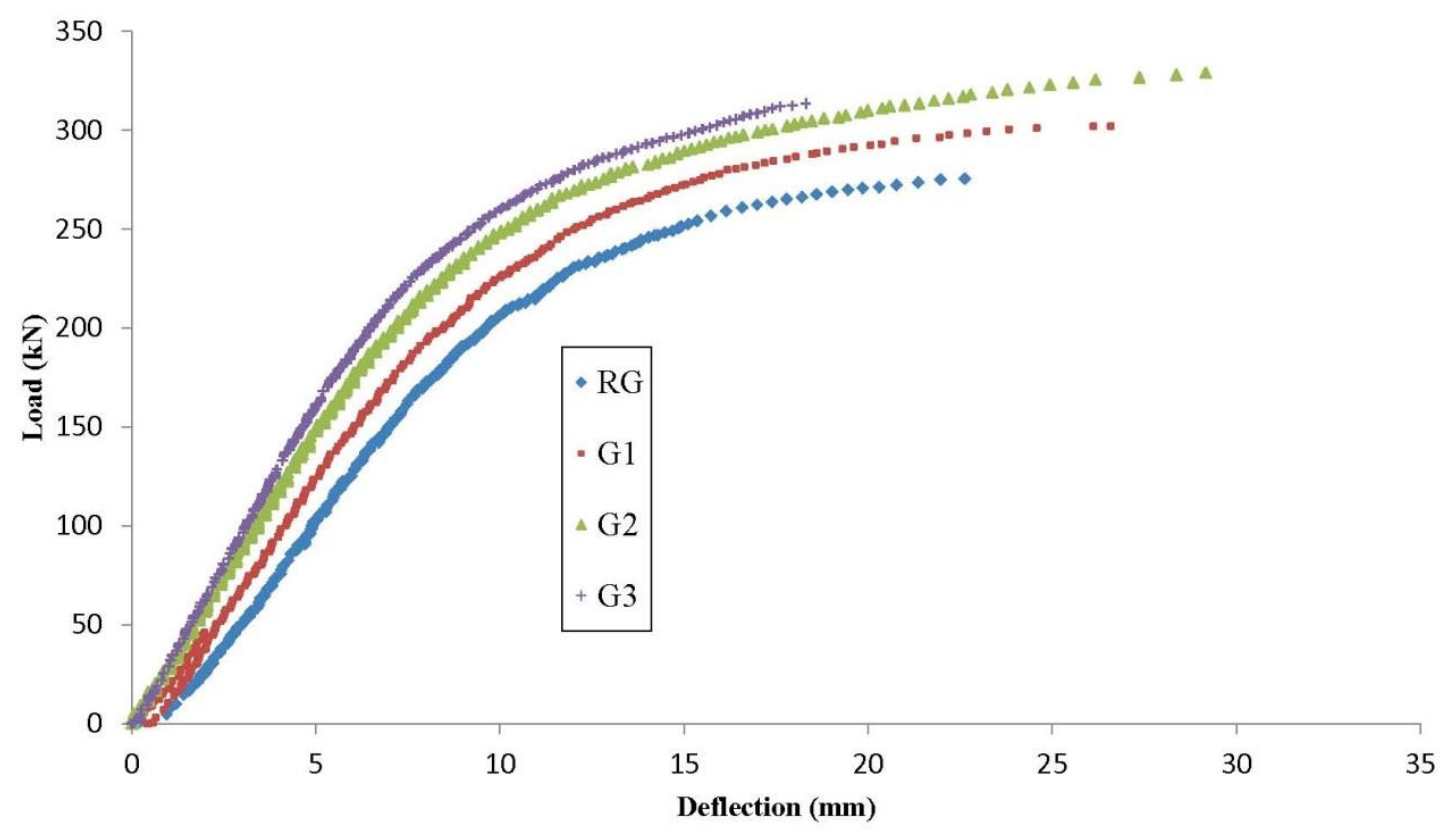

Fig. 4: Load-deflection curve of girders.

\section{Conclusion}

The use of CFRP sheet bonded to top of concrete slab at negative moment region is capable of maintaining the composite action under service load. 
Table 3: Cracking load, yielding load and its ratio.

\begin{tabular}{|c|c|c|c|}
\hline Girder & $\mathrm{P}_{\mathrm{cr}}(\mathrm{kN})$ & $\mathrm{P}_{\mathrm{y}}(\mathrm{kN})$ & $\mathrm{P}_{\mathrm{cr}} / \mathrm{P}_{\mathrm{y}}$ \\
\hline $\mathrm{RG}$ & 77 & 163 & 0.47 \\
\hline $\mathrm{G} 1$ & 123 & 165 & 0.75 \\
\hline $\mathrm{G} 2$ & 136 & 173 & 0.79 \\
\hline $\mathrm{G} 3$ & 150 & 175 & 0.86 \\
\hline
\end{tabular}

\section{Acknowledgements}

The financial support for this work provided by King Fahd University of Petroleum and Minerals, and Deanship of Scientific Research under project number IN121053 gratefully acknowledged.

\section{References}

[1] P. K. Basu, A. M. Sharif and N. U. Ahmad, "Partially pre-stressed continuous composite beams I," Journal of Structural Engineering, vol. 113, no. 9, pp. 1909-1925, 1987.

[2] S. Chen, X. Wang and Y. Jia, "A comparative study of continuous steel-concrete composite beams pre-stressed with external tendons: experimental investigation," Journal of constructional steel research, vol. 65, no. 7, pp. 1480-1489, 2009.

[3] ACI Committee, American Concrete Institute, and International Organization for Standardization, "Building code requirements for structural concrete (ACI 318-08) and commentary," American Concrete Institute, 2008. 